\title{
Novel treatment for critical aortic stenosis with severe aortic root calcification and coronary disease: Combined left internal thoracic artery graft to left anterior descending coronary artery and deployment of transcatheter aortic valve implantation valve under direct vision
}

\author{
Nick Curzen, BM (Hons), PhD, FRCP, ${ }^{\mathrm{a}, \mathrm{b}}$ Paul Diprose, BM, FRCSEd, FRCA, ${ }^{\mathrm{a}}$ Wendy George, ${ }^{\mathrm{a}}$ and \\ Geoff Tsang, MD, FRCS (CTh), ${ }^{\text {a }}$ Southampton, United Kingdom
}

\begin{abstract}
A 78-year-old woman with no previous cardiac history presented to her local hospital in acute pulmonary edema after several weeks of increasing shortness of breath on exertion. A systolic murmur was heard and a subsequent transthoracic echocardiogram showed preserved left ventricular function and calcific aortic stenosis with a Dopplerderived estimated pressure gradient of $70 \mathrm{~mm} \mathrm{Hg}$. She was referred for consideration of surgical aortic valve replacement and underwent coronary angiography as part of the work-up. At fluoroscopy there was severe diffuse circumferential calcification involving the aortic root and ascending aorta (Figure 1), as well as an important stenosis in the mid-left anterior descending (LAD), which itself was heavily calcified and extremely tortuous. The case was discussed at a multidisciplinary team meeting and a conventional aortic valve replacement was deemed unattractive because of the degree of aortic root calcification. Furthermore, the appearance of the LAD made percutaneous treatment of this lesion technically challenging. It therefore was decided that surgery should be performed to replace the aortic valve using a transcatheter aortic valve implantation (TAVI) under direct vision, and graft the LAD artery using a left internal thoracic conduit.
\end{abstract}

Surgery was performed through a median sternotomy on cardiopulmonary bypass. The left internal thoracic artery was harvested and sewn on to the LAD uneventfully. A high transverse aortotomy then was performed and the heavily calcified aortic valve was visualized. Several calcific masses were removed from the root. A 26-mm Edwards Sapien TAVI valve (Edwards Lifesciences, Irvine, Calif) mounted on a transfemoral delivery system was

\footnotetext{
From the Wessex Cardiothoracic Centre, ${ }^{\text {a }}$ University Hospital Southampton NHS Foundation Trust, Southampton, United Kingdom; Faculty of Medicine, ${ }^{\mathrm{b}}$ University of Southampton, Southampton, United Kingdom.

Disclosures: Authors have nothing to disclose with regard to commercial support.

Received for publication May 8, 2013; accepted for publication July 19, 2013; available ahead of print Sept 16, 2013

Address for reprints: Nick Curzen, BM (Hons), PhD, FRCP, Wessex Cardiothoracic Unit, University Hospital Southampton NHS Foundation Trust, Tremona Rd,

Southampton SO16 6YD, United Kingdom (E-mail: nick.curzen@uhs.nhs.uk).

J Thorac Cardiovasc Surg 2013;146:e53-4

$0022-5223 / \$ 36.00$

Copyright (c) 2013 by The American Association for Thoracic Surgery

http://dx.doi.org/10.1016/j.jtcvs.2013.07.037
}

positioned and deployed under direct vision (Figure 2), and the aortotomy was closed with 4.0 Prolene (Ethicon, Inc, Somerville, NJ) suture.

The procedure was uncomplicated and the patient had an uneventful recovery apart from transient atrial fibrillation. Post-procedure echocardiography confirmed successful position and function of the TAVI valve.

\section{DISCUSSION}

The role of TAVI in the treatment of severe aortic stenosis in symptomatic patients either unsuitable for conventional aortic valve replacement, or at very high risk for it, is now well established by high-quality randomized trials. ${ }^{1,2}$ Recent modifications of the TAVI technique include the transaortic approach for patients with restricted vascular access, although issues relating to aortic calcification and its distribution remain a concern in some

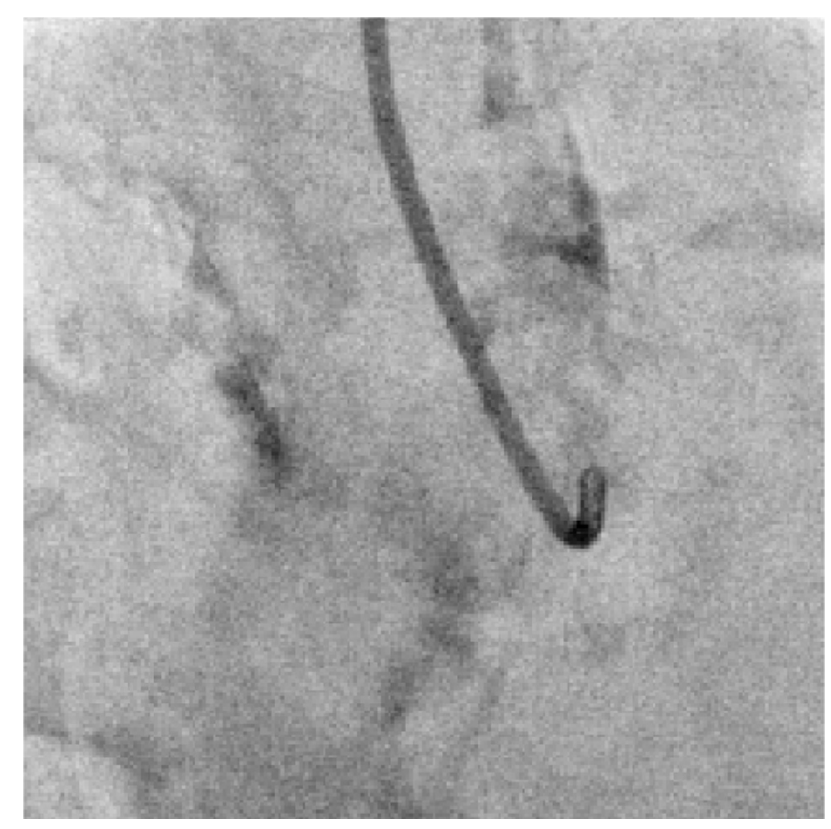

FIGURE 1. Right anterior oblique fluoroscopic image showing extensive calcification involving the aortic root and ascending aorta. The catheter is sitting in the orifice of the right coronary artery. 

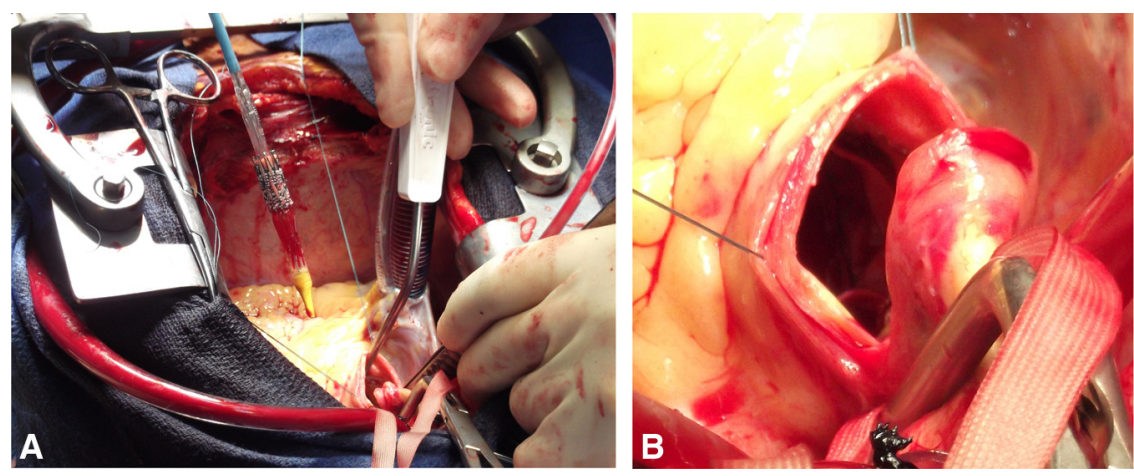

FIGURE 2. A, Image from head end showing aortotomy and transfemoral 26-mm Edwards Sapien TAVI valve being prepared for positioning under direct vision. B, Close-up view through aortotomy showing TAVI valve after successful deployment.

patients. $^{3}$ The combination of transaortic TAVI and coronary bypass surgery also has been reported. ${ }^{4} \mathrm{We}$ describe a case in which the extent of circumferential aortic calcification presented a considerable technical challenge for conventional aortic valve surgery, but in a patient in whom LAD disease also was believed to be very difficult to manage by percutaneous coronary intervention. It therefore was decided, given our familiarity with TAVI, that we should make use of the transfemoral TAVI valve and delivery system to replace the aortic valve at the same time the left internal thoracic artery to LAD was performed, thus avoiding the requirement for suturing at the level of the dense aortic calcification. The utility of a TAVI valve in this case highlights the potential in clinical practice for sutureless aortic valve prostheses.

\section{References}

1. Leon M, Smith C, Mack M, Miller DC, Moses JW, Svensson LG, et al. Transcatheter aortic-valve implantation for aortic stenosis in patients who cannot undergo surgery. N Engl J Med. 2010;363:1597-607.

2. Smith C, Leon M, Mack M, Miller DC, Moses JW, Svensson LG, et al. Transcatheter versus surgical aortic-valve replacement in high-risk patients. $N$ Engl J Med. 2011;364:2187-98.

3. Bapat V, Attia R, Thomas M. Distribution of calcium in the ascending aorta in patients undergoing transcatheter aortic valve implantation and its relevance to the transaortic approach. JACC Cardiovasc Interv. 2012;5:470-6.

4. Wiegerinck E, Cocchieri R, Baan J Jr, de Mol BA. Hybrid coronary artery bypass grafting and transaortic transcatheter aortic valve implantation. J Thorac Cardiovasc Surg. 2013;145:600-2.

\title{
Four-year follow-up after thoracic endovascular aortic repair for symptomatic thoracoabdominal aneurysm through the off-label use of a bifurcated abdominal endograft
}

\author{
Mario Marino, MD, Holta Kasemi, MD, Enrico Sbarigia, MD, and Francesco Speziale, MD, Rome, Italy
}

Thoracic endovascular aortic repair has become an alternative to the open surgical or to the hybrid approach for thoracoabdominal aortic aneurysm (TAAA) treatment. ${ }^{1}$ Fenestrated and branched endografts allow the exclusion

\footnotetext{
From the Vascular Surgery Unit, Department "Paride Stefanini," Sapienza University of Rome, Rome, Italy.

Disclosures: Authors have nothing to disclose with regard to commercial support.

Received for publication May 20, 2013; revisions received July 3, 2013; accepted for publication July 26, 2013; available ahead of print Sept 16, 2013.

Address for reprints: Holta Kasemi, MD, Vascular Surgery Unit, Department "Paride Stefanini", Sapienza University of Rome, Policlinico Umberto I, Viale del Policlinico 165, 00161, Rome, Italy (E-mail: kasemiholta@libero.it).

J Thorac Cardiovasc Surg 2013;146:e54-6

$0022-5223 / \$ 36.00$

Copyright (c) 2013 by The American Association for Thoracic Surgery

http://dx.doi.org/10.1016/j.jtcvs.2013.07.059
}

of the aneurysm and perfusion of the visceral arteries. Unfortunately, these devices require from 4 to 6 weeks for manufacture, an unsafely long wait for a symptomatic or ruptured TAAA. In an emergency setting, the use of offthe shelf devices of standardized design permits treatment of more than $80 \%$ of TAAAs. ${ }^{2}$ Homemade devices have been reported for urgent TAAA repair. ${ }^{3}$ In addition, the chimney and sandwich endovascular techniques remain a valid alternative for patients with symptomatic or ruptured TAAA.

We report the 4-year follow-up of a high-risk patient with symptomatic TAAA treated with an unusual endovascular technique: off-label use of a device manufactured for infrarenal aortic aneurysm repair. 